\title{
Erratum to: Interplay of Circadian Rhythms and Light in the Regulation of Photosynthesis-Derived Metabolism
}

Matthew A. Jones

Erratum to:

(C) Springer International Publishing AG 2017

Progress in Botany, DOI 10.1007/124_2017_2

The Figure 1 in this chapter was inadvertently published with a wrong version.

The correct version of the Figure 1 is shown below.

The updated online version for this chapter can be found under http://dx.doi.org/10.1007/124_2017_2

Communicated by Ulrich Lüttge

M.A. Jones ( $\square)$

School of Biological Sciences, University of Essex, Colchester, UK

e-mail: matthew.jones@essex.ac.uk

(C) Springer International Publishing AG 2017

Progress in Botany, DOI 10.1007/124_2017_12 


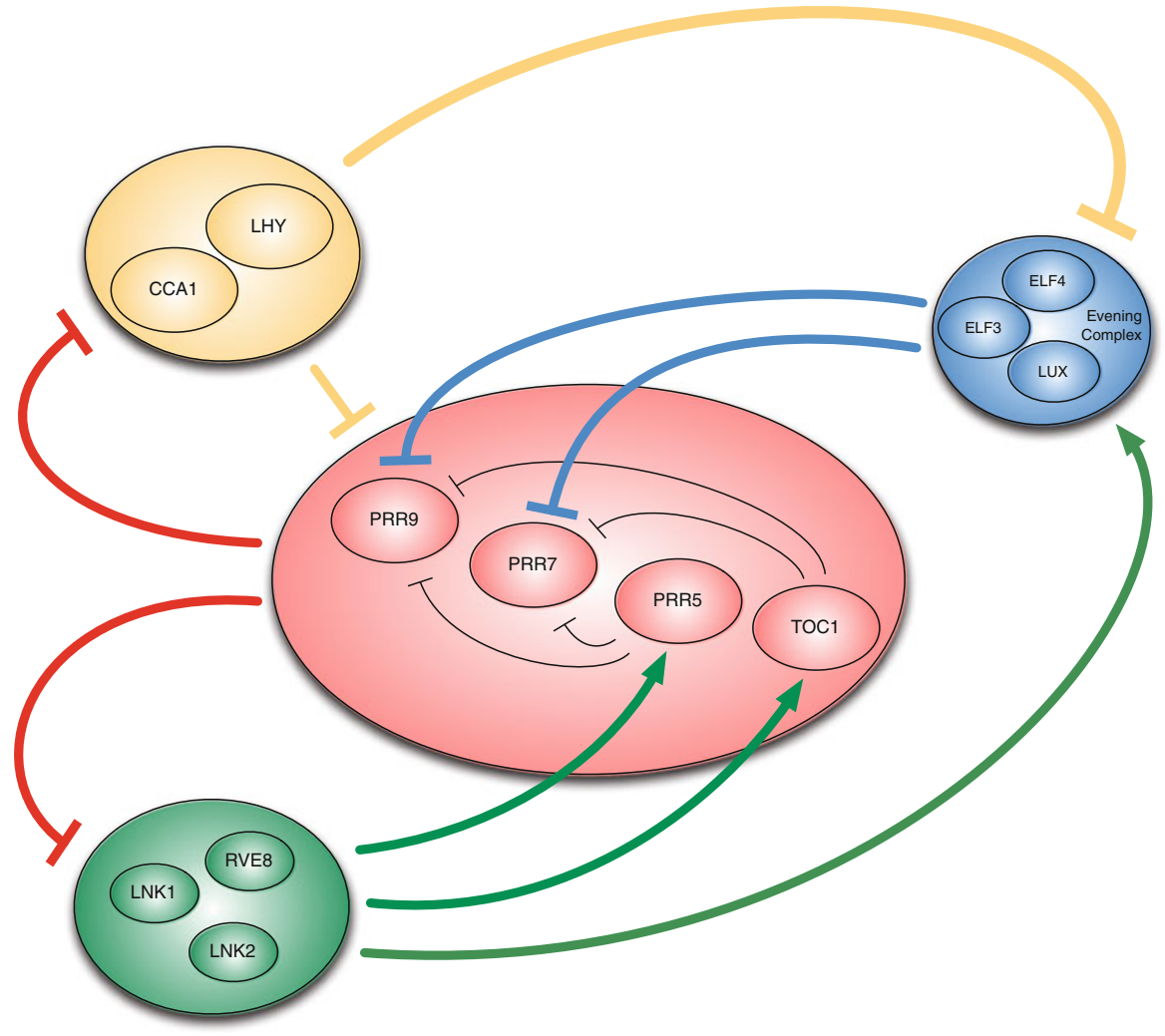

The original article was corrected. 